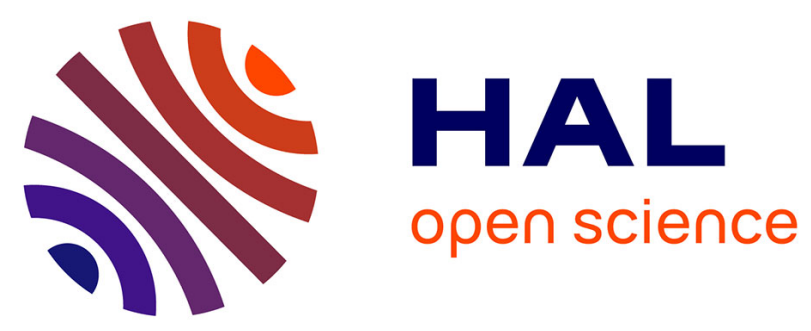

\title{
Simulation of Eu3+ luminescence spectra of borosilicate glasses by molecular dynamics calculations
}

\author{
J. de Bonfils, G. Panczer, D. de Ligny, S. Peuget, J.-M. Delaye, Stéphane
}

Chaussedent, Andre Monteil, B. Champagnon

\section{- To cite this version:}

J. de Bonfils, G. Panczer, D. de Ligny, S. Peuget, J.-M. Delaye, et al.. Simulation of Eu3+ luminescence spectra of borosilicate glasses by molecular dynamics calculations. Optical Materials, 2008, 30 (11), pp.1689 - 1693. 10.1016/j.optmat.2007.07.009 . hal-03436301

\section{HAL Id: hal-03436301 \\ https://univ-angers.hal.science/hal-03436301}

Submitted on 19 Nov 2021

HAL is a multi-disciplinary open access archive for the deposit and dissemination of scientific research documents, whether they are published or not. The documents may come from teaching and research institutions in France or abroad, or from public or private research centers.
L'archive ouverte pluridisciplinaire HAL, est destinée au dépôt et à la diffusion de documents scientifiques de niveau recherche, publiés ou non, émanant des établissements d'enseignement et de recherche français ou étrangers, des laboratoires publics ou privés. 


\title{
Simulation of $\mathrm{Eu}^{3+}$ luminescence spectra of borosilicate glasses by molecular dynamics calculations
}

\author{
J. de Bonfils ${ }^{\mathrm{a}, *}$, G. Panczer ${ }^{\mathrm{a}}$, D. de Ligny ${ }^{\mathrm{a}}$, S. Peuget ${ }^{\mathrm{b}}$, J.-M. Delaye $^{\mathrm{b}}$, S. Chaussedent ${ }^{\mathrm{c}}$, \\ A. Monteil ${ }^{\mathrm{c}}$, B. Champagnon ${ }^{\mathrm{a}}$ \\ ${ }^{a}$ CNRS, UMR5620, Laboratoire de Physico-Chimie des Matériaux Luminescents, Bât. G. LIPPMANN-12 rue Ampère, \\ Domaine Scientifique de la Doua, Villeurbanne F-69622, France \\ ${ }^{\mathrm{b}}$ Commissariat à l'Énergie Atomique, CEA Marcoule, DEN/DTCD, BP 17171, 30207 Bagnols-sur-Cèze Cedex, France \\ ${ }^{\mathrm{c}}$ Laboratoire POMA UMR CNRS 6136, Université d'Angers, 2, bd Lavoisier, F-49045 Angers cedex, France
}

Available online 31 December 2007

\begin{abstract}
Simplified inactive rare-earths doped nuclear waste glasses have been obtained by molecular dynamics (MD) simulation in order to investigate the local structure around the rare-earth by luminescence studies. MD calculations were performed with modified BornMayer-Huggins potentials and three body angular terms representing Coulomb and covalent interactions. Atomic positions within the glasses are then determined. Simulations of luminescence spectra were then obtained by calculation of the ligand field parameters affecting each luminescent ion. Considering the $C_{2 v}$ symmetry, it is possible to calculate the radiative transition probabilities between the emitter level, ${ }^{5} \mathrm{D}_{0}$, and the splitted receptor levels, ${ }^{7} \mathrm{~F}_{J}(J=0-3)$ for each $\mathrm{Eu}^{3+}$ ion. The simulated emission spectra are obtained by convolution of all the $\mathrm{Eu}^{3+}$ ions contributions. A comparison with the experimental data issue from fluorescence line narrowing and microluminescence spectroscopies allowed us not only to validate the simulation of luminescence spectra from simulated environments, but also to confirm the presence and the identification of two major $\mathrm{Eu}^{3+}$ sites distribution in the nuclear glasses thanks to spectra-structure correlations.
\end{abstract}

(C) 2007 Elsevier B.V. All rights reserved.

PACS: 71.15.Pd; 73.61.Jc; 78.55.-m

Keywords: Luminescence; $\mathrm{Eu}^{3+}$ local environment; Molecular dynamics simulation

\section{Introduction}

Rare-earth (RE) doped glasses are well known candidates for many applications as optical fibre amplification, upconversion laser and many other applications [1-4]. $\mathrm{Eu}^{3+}$ ions are more particularly used as luminescent probe in nuclear waste glasses [5-8] since $\mathrm{Eu}^{3+}$ ion acts as an analogue of minor actinides [9] and are found also as fission products in nuclear waste glasses. In the recent years

\footnotetext{
* Corresponding author. Tel.: +33 4 72448221; fax: +33 472448442 .

E-mail address: jdebonfils@pcml.univ-lyon1.fr (J. de Bonfils).
}

the use of the molecular dynamics (MD) technique has become very common in glasses studies, especially in the determination of local structure around rare-earth [10]. Changes in the local environment of the $\mathrm{Eu}^{3+}$ ions in glasses are known to lead to strong modifications in optical properties. Luminescence spectroscopy allows us to follow the structural modification of the local environment around the rare-earth but does not offer the knowledge of the structure as MD technique does. The goal of this work is thus to investigate the $\mathrm{Eu}^{3+}$ local structure evolution for different inactive simplified nuclear glasses by MD simulations coupled to emission spectra calculations. 


\section{Methods and techniques}

\subsection{Generation of simulated emission spectra}

The following procedure was used to calculate emission spectra of $\mathrm{Eu}^{3+}$ ions in the simulated borosilicate glasses. The point-charge model is used to describe the crystal field where the atoms of the lattice are represented only by point charges. This model is simple and provides results with quite good accuracy though it neglects some interactions between luminescent ions and the glassy matrix. These interactions will be discussed later.

Each luminescent ion is considered as a punctual charge positioned at the origin of a coordinate system. The electrostatic potential due to the surrounding ions considered as punctual charges can be developed and decomposed in series of $A_{n m}$ parameters as follows:

$A_{n m}=-\mathrm{e}^{2} \sum_{j} \frac{q_{j}}{R_{j}^{n+1}}(-1)^{m} C_{-m}^{(n)}\left(\vec{R}_{j}\right)$,

where the sum is realized on all the nearby ions (limited within a cut-off radius), $\vec{R}_{j}$ are the position vectors (given by MD calculations) and $q_{j}$ the effective charges of the atoms. Effective charges are adjusted following the works of Mo et al. [11] for $q_{\mathrm{Al}}, q_{\mathrm{O}}$, Zhao et al. [12] for $q_{\mathrm{Zr}}, q_{\mathrm{O}}$, Wemple et al. [13] for $q_{\mathrm{Ca}}, q_{\mathrm{O}}$ and Sen et al. [14] for $q_{\mathrm{Si}}, q_{\mathrm{O}}, q_{\mathrm{B}}$ and $q_{\mathrm{Na}} . C_{-m}^{(n)}$ are the irreductible spherical tensors. Crystal field parameters are calculated from the $A_{n m}$ values with respect of Eq. (2). $\rho_{\mathrm{n}}$ is a constant determined by the nature of the rare-earth.

$B_{n m}=\rho_{\mathrm{n}} A_{n m}$

$B_{n m}$ even terms coupled to a Hamiltonian perturbation term are used for the degeneracy lift of the energy levels. Odd terms lead to the calculation of the transition probabilities of dipolar electric transitions. Thus, we obtained all Stark sublevels energies for the ${ }^{7} F_{0}$ to ${ }^{5} F_{6}$ levels for each luminescent ion.

Transitions probabilities are given for a luminescent ion $k$ by

$A_{k, a b}=\frac{\mathrm{e}^{2}}{4 \pi^{3} \epsilon_{0}} \frac{32 \pi^{3} \sigma_{a b}^{3}}{3 \bar{h}}\left[\frac{n\left(n^{2}+2\right)^{2}}{9} S_{a b}^{\mathrm{DE}}+n^{3} S_{a b}^{\mathrm{DM}}\right]$

where $a$ and $b$ are the emitter and receptor levels, $S^{\mathrm{DE}}$ and $S^{\mathrm{DM}}$ are dipolar electric and dipolar magnetic strength lines of the radiative transitions. Intensities $I_{k, a b}$ are given by

$I_{k, a b}=F_{j} \beta_{k, a b} A_{k, a b}$

where $F_{j}$ is a scale factor and $\beta_{k, a b}$ is the branch ratio.

Convolution of all the calculated intensities for all $\mathrm{Eu}^{3+}$ ions by Lorentzian functions is realized to obtain the spectral shape of the simulated luminescence spectra.

\subsection{Molecular dynamics simulations}

Considered glasses were obtained by molecular dynamics simulations. The glasses compositions are summarized
Table 1

Simulation parameters for the $\mathrm{CJ} x: \mathrm{Eu}^{3+}$ glasses $(x=1,3,7)$

\begin{tabular}{llll}
\hline & $\mathrm{CJ} 1: \mathrm{Eu}^{3+}$ & $\mathrm{CJ} 3: \mathrm{Eu}^{3+}$ & $\mathrm{CJ} 7: \mathrm{Eu}^{3+}$ \\
\hline Number of Si ions & 1809 & 1621 & 1653 \\
Number of O ions & 5463 & 5421 & 5462 \\
Number of B ions & 927 & 864 & 880 \\
Number of Na ions & 747 & 681 & 695 \\
Number of Al ions & - & 206 & 210 \\
Number of Ca ions & - & 154 & - \\
Number of $\mathrm{Zr}$ ions & - & - & 47 \\
Number of Eu ions & 54 & 53 & 53 \\
Length of box side $(\AA)$ & 48.335 & 47.945 & 48.600 \\
Density $\left(\mathrm{g} / \mathrm{cm}^{3}\right)$ & 2.554 & 2.669 & 2.566 \\
\hline
\end{tabular}

Table 2

Chemical composition ( $\%$ molar oxide) of the glasses

\begin{tabular}{llllllll}
\hline & $\mathrm{SiO}_{2}$ & $\mathrm{~B}_{2} \mathrm{O}_{3}$ & $\mathrm{Al}_{2} \mathrm{O}_{3}$ & $\mathrm{Na}_{2} \mathrm{O}$ & $\mathrm{CaO}$ & $\mathrm{ZrO}_{2}$ & $\mathrm{Eu}_{2} \mathrm{O}_{3}$ \\
\hline $\mathrm{CJ} 1: \mathrm{Eu}^{3+}$ & 67.09 & 17.83 & - & 14.08 & - & - & 1.00 \\
$\mathrm{CJ} 3: \mathrm{Eu}^{3+}$ & 60.55 & 16.13 & 3.85 & 12.72 & 5.75 & - & 1.00 \\
$\mathrm{CJ} 7: \mathrm{Eu}^{3+}$ & 63.13 & 16.81 & 4.01 & 13.26 & - & 1.79 & 1.00 \\
\hline
\end{tabular}

in Table 1 with respect to the experimental ones mentioned inTable 2. The simulated cubic cell contains a total amount of 9000 atoms. Interactions in glasses are mainly represented by an association of Born-Mayer-Huggins potentials (Eq. (5)) and a three body angular term (Eq. (6)). These two terms represent, respectively Coulomb interactions and covalent interactions [15-17]

$\phi\left(r_{i j}\right)=A \cdot \exp \left(-\frac{r_{i j}}{\rho}\right)+\frac{q_{i} \cdot q_{j}}{r_{i j}} \cdot \operatorname{erfc}\left(\alpha \cdot r_{i j}\right)-\frac{C}{r_{i j}^{6}}+\frac{D}{r_{i j}^{8}}$,

$\phi\left(r_{i j}, r_{i k}, \theta_{j i k}\right)=\lambda \cdot \exp \left(\frac{\gamma}{r_{i j}-r_{c}}+\frac{\gamma}{r_{i k}-r_{c}}\right) \cdot\left(\cos \theta_{j i k}-\cos \theta_{0}\right)^{2}$,

where $r_{i j}$ and $r_{i k}$ are the interatomic distances, $q_{i}$ and $q_{j}$ the charges, $\alpha$ a constant and $\theta_{j i k}$ the angle formed by an atom triplet $j-i-k$; adjustable parameters are $A, D, C, \rho, \lambda$ and $\gamma$ which depend on the nature of atoms involved. $C, D$ are all equal to zero except for $\mathrm{Na}-\mathrm{O}, \mathrm{Ca}-\mathrm{O}$ and $\mathrm{Eu}-\mathrm{O}$ interactions (Table 3). Non-zero values for these interactions allowed us to obtain better fit of the potentials with experimental data by introducing $-1 / r^{6}$ and $1 / r^{8}$ terms. Complete Ewald sum is performed to take into account the long range component of the Coulomb interactions.

Modelized glasses were prepared by quenching a liquid equilibrated at high temperature between 4000 and $6000 \mathrm{~K}$. After stabilization of the liquid at high tempera-

Table 3

Simulation parameters used for the potential function in the case of $\mathrm{Eu}-\mathrm{O}$ interactions

\begin{tabular}{llllllll}
\hline & $A(\mathrm{eV})$ & $C\left(\mathrm{eV}^{6}\right)$ & $D\left(\mathrm{eV}^{8}\right)$ & $\rho(\AA)$ & $\alpha$ & $q_{\mathrm{Eu}}^{3+}$ & $q_{\mathrm{O}}^{2-}$ \\
\hline $\mathrm{CJ} 1: \mathrm{Eu}^{3+}$ & & & & & & & \\
$\mathrm{CJ} 3: \mathrm{Eu}^{3+}$ & 52,360 & 1553 & 7141 & 0.1899 & 0.2627 & $+3 \mathrm{e}$ & $-2 \mathrm{e}$ \\
$\mathrm{CJ} 7: \mathrm{Eu}^{3+}$ & & & & & & & \\
\hline
\end{tabular}


ture $(15,000$ time steps among a total of 87,000 time steps, a time step is equal to $10^{-15} \mathrm{~s}$ ), we proceeded to constant quenching $\left(10^{14} \mathrm{~K} \mathrm{~s}^{-1}\right)$ until the system reached room temperature. Finally, a relaxation is performed during 15,000 time steps at ambient temperature. The volume is kept constant during the preparation of the glasses and adjusted to anneal the final pressure.

\section{Results and discussion}

\subsection{Emission spectra simulation}

The $C_{2 v}$ symmetry group is retained for our work because it is the highest symmetry in which the full splitting of the ${ }^{7} F_{1,2}$ levels is observed $[2,18]$. Fig. 1 shows a comparison of the experimental and simulated emission spectra of the ${ }^{5} \mathrm{D}_{0} \rightarrow{ }^{7} \mathrm{~F}_{J}(J=0-3)$ transitions for the three glasses. ${ }^{5} \mathrm{D}_{0} \rightarrow{ }^{7} \mathrm{~F}_{4,5,6}$ transitions have been also calculated although they are not shown on the figure for reasons of clarity. MD data (atomic positions) used for these simulations are those calculated at a quenching rate of $10^{14} \mathrm{~K} \mathrm{~s}^{-1}$.

Simulated spectra present a good overall agreement with experimental ones. The dissymmetric shape of the ${ }^{5} \mathrm{D}_{0} \rightarrow{ }^{7} \mathrm{~F}_{0}$ transition is extremely well reproduced, and all transitions are well positioned. One can note that the ${ }^{5} \mathrm{D}_{1} \rightarrow{ }^{7} \mathrm{~F}_{4}$ transition should be positioned inside range of the ${ }^{5} \mathrm{D}_{0} \rightarrow{ }^{7} \mathrm{~F}_{2}$ transition in solids-state components. According to Layne et al. [19] such transition is not possible due to very efficient multiphonon processes which induce non-radiative ${ }^{5} \mathrm{D}_{1} \rightarrow{ }^{5} \mathrm{D}_{0}$ transitions. Some discrepancies are also observable on Fig. 1 and more particularly in the ${ }^{5} \mathrm{D}_{0} \rightarrow{ }^{7} \mathrm{~F}_{2}$ transition. These differences have probably two origins. First, the point charge model takes into account only ionic interactions and not covalent ones. Second, according to Cormier et al. [20], the considered electrostatic field is an average field which assumes that all dynamics events, like vibronic coupling or energy transfer, are not include in the simulation of spectra. That is the reason why some Stark sublevels intensities calculations failed especially for the ${ }^{5} \mathrm{D}_{0} \rightarrow{ }^{7} \mathrm{~F}_{2}$ transition. However, good agreement is observed between the ${ }^{5} \mathrm{D}_{0} \rightarrow{ }^{7} \mathrm{~F}_{1}$ simulated and experimental transitions except in the small difference in the width.

The comparison between full width at half maximum (FWHM) of the ${ }^{5} \mathrm{D}_{0} \rightarrow{ }^{7} \mathrm{~F}_{0}$ transition between simulated and experimental glasses is shown on Fig. 2. One can observe a good agreement of the calculation with the experience $\left(r^{2}=95 \%\right)$ within the error bars. Thus, we can
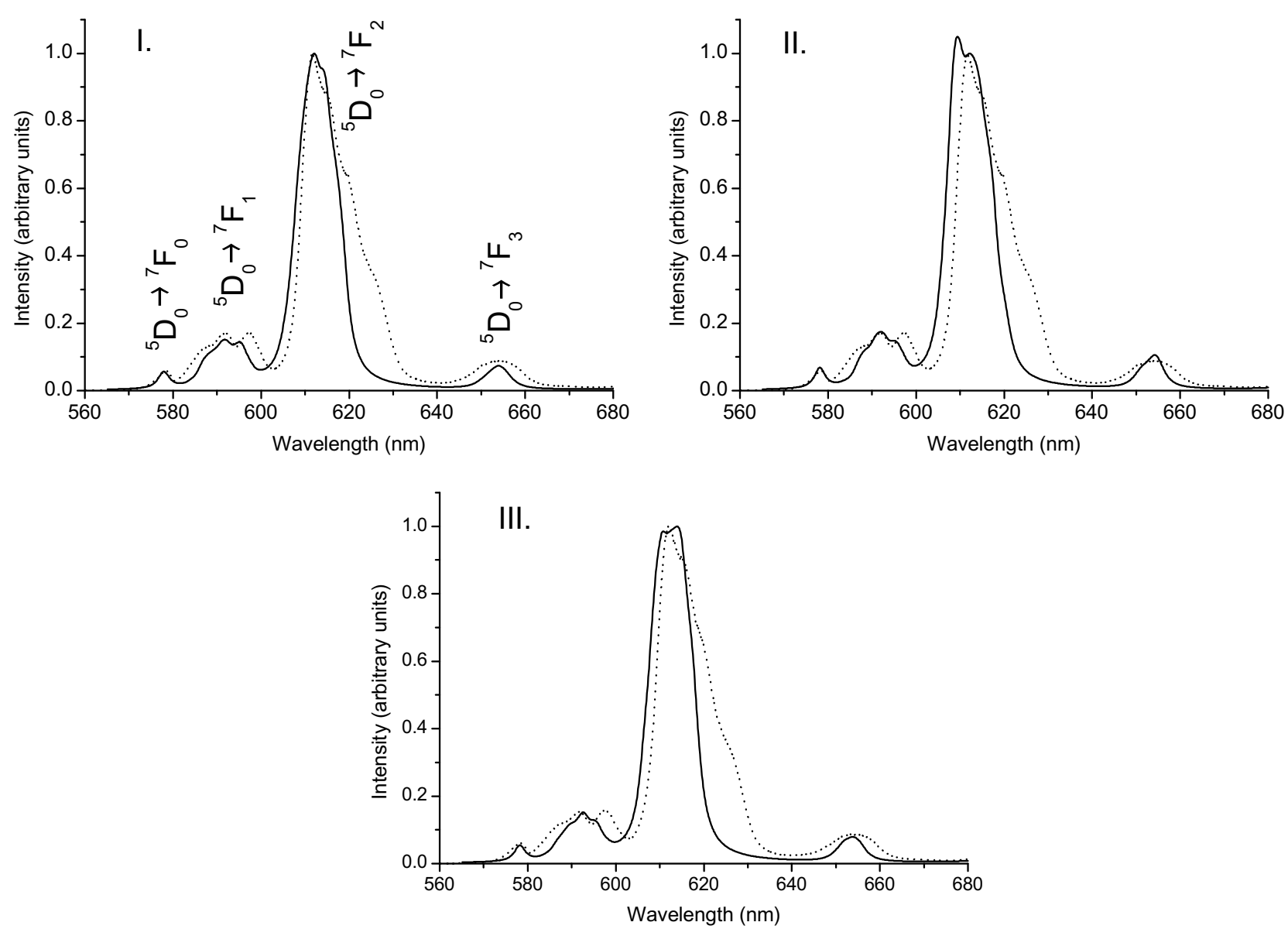

Fig. 1. Comparison between experimental (dotted lines) and simulated (solid lines) emission spectra of $\mathrm{Eu}^{3+}$ in CJ glasses (I. CJ1:Eu $^{3+}, \mathrm{II} \mathrm{CJ} 3: \mathrm{Eu}^{3+}$, III. $\left.\mathrm{CJ} 7: \mathrm{Eu}^{3+}\right)$ at room temperature. 


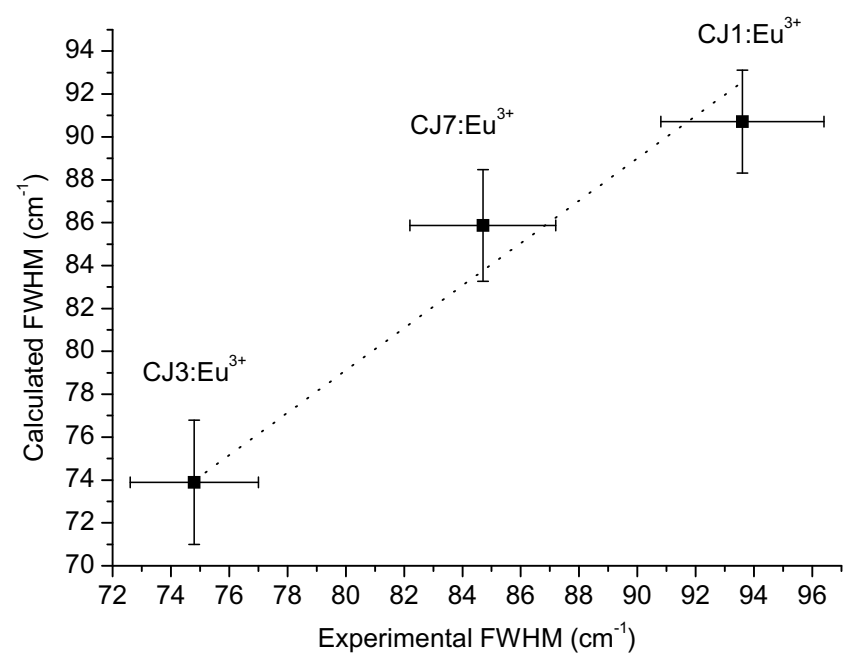

Fig. 2. Comparison between calculated and experimental full widths at half maximum of the $\mathrm{Eu}^{3+}{ }^{5} \mathrm{D}_{0} \rightarrow{ }^{7} \mathrm{~F}_{0}$ transition for the three studied glasses. Dotted line shows the points corresponding to the linear function $y=x\left(r^{2}=0.95\right)$.

assume that our MD results are correct and our $C_{2 v}$ symmetry group assumption was right. FWHM variations between glasses can be explained in terms of chemical composition effects. Indeed, assuming that $\mathrm{Ca}^{2+}$ only creates non-bridging oxygens due to its large field strength [21] and that the RE acts preferentially as a charge compensator for $\mathrm{Al}^{3+}[22-24]$ (the six-coordinated $\mathrm{Zr}^{4+}$ is compensated by $\mathrm{Na}^{+}$), we deduce that our glasses are classified in terms of increasing depolymerisation as follows: $\mathrm{CJ} 1: \mathrm{Eu}^{3+} \rightarrow \mathrm{CJ} 7: \mathrm{Eu}^{3+} \rightarrow \mathrm{CJ} 3: \mathrm{Eu}^{3+}$. In glasses, depolymerisation should be seen as bond breaking between polyhedrons of the glassy network by modifiers oxides which transform bridging oxygens (i.e. oxygens linked to two former elements) into non-bridging oxygens (i.e. oxygens linked to only one former element). Intuiting that more the glass is depolymerised, more $\mathrm{Eu}^{3+}$ define its environment, therefore $\mathrm{Eu}^{3+}$ local structures are more similar when depolymerisation increases. The ${ }^{5} \mathrm{D}_{0} \rightarrow{ }^{7} \mathrm{~F}_{0}$ FWHM is then lower for increasing depolymerised glasses.

\subsection{Molecular dynamics simulations}

Thanks to the validation of our MD model by the generation of luminescence spectra, we can now analyse the MD data. MD calculations were realized at a quenching rate of $10^{14} \mathrm{~K} \mathrm{~s}^{-1}$ for all the three simulated samples according to the parameters mentioned in Table 1. Fig. 3 shows the evolution of the $\mathrm{Si} / \mathrm{B}$ atomic ratio as a function of the $\mathrm{Eu}^{3+}$ local environment. This ratio indicates whether the $\mathrm{Eu}^{3+}$ ions are mainly surrounded by $\mathrm{Si}$ second neighbours (high $\mathrm{Si} / \mathrm{B}$ ratios) or by $\mathrm{B}$ second neighbours (low $\mathrm{Si} / \mathrm{B}$ ratios). A first site population can be extract from high ratio values $(\mathrm{Si} / \mathrm{B}>5)$ which corresponds to $\mathrm{Si}$ rich environment (about $15 \%$ of the $\mathrm{Eu}^{3+}$ ions). This category is present in all the 3 studied glasses. The second site population corresponds to low $\mathrm{Si} / \mathrm{B}$ ratio values and indicates in

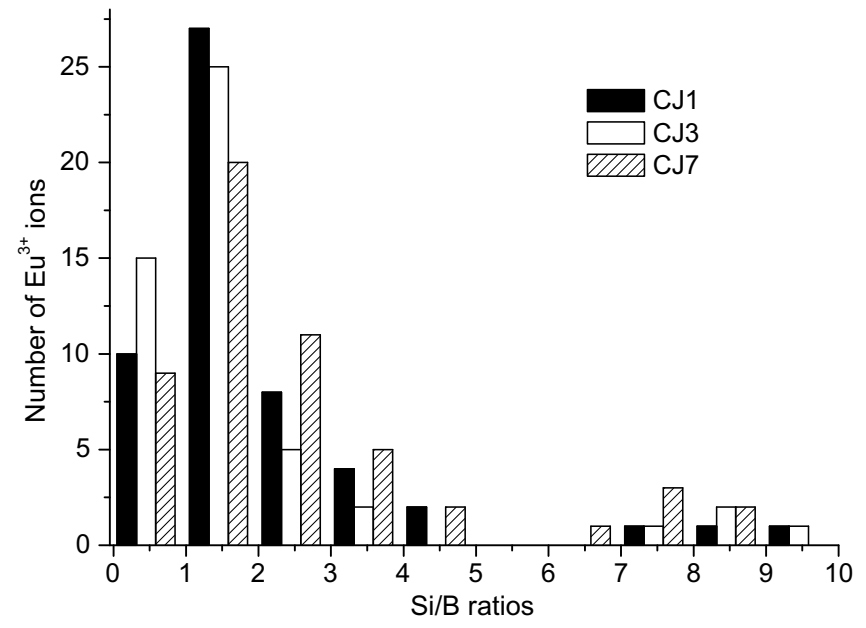

Fig. 3. Determination of the $\mathrm{Eu}^{3+}$ local environment obtained by simulation. Black, white and hatched bars are, respectively related to $\mathrm{CJ} 1: \mathrm{Eu}^{3+}, \mathrm{CJ} 3: \mathrm{Eu}^{3+}$ and $\mathrm{CJ} 7: \mathrm{Eu}^{3+}$.

studied samples the presence of a mixed $\mathrm{Si}-\mathrm{B}$ environment. Moreover, one can note that no $\mathrm{Eu}^{3+}$ is in pure borate environment. Considering $\mathrm{CJ} 3-7: \mathrm{Eu}^{3+}$, Al second neighbour atoms are in a few amounts around the RE (less than $8 \%$ of $\mathrm{Eu}^{3+}$ have two or more $\mathrm{Al}$ atoms in their neighbourhood) and do not seem to prefer one to the other environment. Accordingly, comparing our data with a previous work [5], we are able to clarify the nature of the two major environment in those glasses. Indeed, in the previous work we supposed that we had a mixed Al-B environment, in fact, we notice the presence of Al but the environment is clearly a mixed $\mathrm{Si}-\mathrm{B}$ one. The $\mathrm{Si}$ rich environment found by experience is confirmed by MD calculations. The amount of $\mathrm{Eu}^{3+}$ ions in a silicate rich environment increases when the glass is more complex $\left(\mathrm{CJ} 7: \mathrm{Eu}^{3+}>\right.$ $\left.\mathrm{CJ} 3: \mathrm{Eu}^{3+}>\mathrm{CJ} 1: \mathrm{Eu}^{3+}\right)$ : starting from $5.6 \%$ of the $\mathrm{Eu}^{3+}$ in $\mathrm{CJ} 1: \mathrm{Eu}^{3+}$ to $11.3 \%$ in the case of $\mathrm{CJ} 7: \mathrm{Eu}^{3+}$. Moreover, one can note that a larger amount of modifiers oxides leads to a better separation of the $\mathrm{Si} / \mathrm{B}$ ratios and thus to a better separation of the two major environments. Finally, more than $80 \%$ of the $\mathrm{Eu}^{3+}$ ions are present in a $\mathrm{Si}-\mathrm{B}$ environment with the ratio lower than 3 . This result indicates that most of $\mathrm{Eu}^{3+}$ ions tend to be either in a region located on the border line between the silicate rich and the borate rich domains, either in a mixed $\mathrm{Si}-\mathrm{B}$ region. Finally, no europium clustering has been observed in our simulated samples.

\section{Conclusion}

The molecular dynamic technique allowed us to simulate different $\mathrm{Eu}^{3+}$ doped borosilicate glasses. Using a point-charge model, we were able to calculate the electronic energy levels as well as transition probabilities of the simulated $\mathrm{Eu}^{3+}$ in glasses resulting in simulation of emission spectra. Comparisons between experimental and simulated spectra and more precisely between calculated and experi- 
mental FWHM of the ${ }^{5} \mathrm{D}_{0} \rightarrow{ }^{7} \mathrm{~F}_{0}$ transition allowed us to validate the MD model and its results for our glasses.

We found, in the three simplified nuclear glasses, two different distributions of $\mathrm{Eu}^{3+}$ environment. The two major environments were clearly identified as a silicate rich one and a mixed silicate-borate one. More than $80 \%$ of $\mathrm{Eu}^{3+}$ ions are located in the mixed environment. Concerning $\mathrm{CJ} 3: \mathrm{Eu}^{3+}$ and $\mathrm{CJ} 7: \mathrm{Eu}^{3+}$, the presence of $\mathrm{Al}$ atoms is observed in both two environments in very low amounts closed to the RE.

\section{References}

[1] G. Pucker, K. Gatterer, H.P. Fritzer, M. Bettinelli, M. Ferrari, Phys. Rev. B 53 (1996) 6225.

[2] C. Brecher, L.A. Riseberg, Phys. Rev. B 13 (1976) 81.

[3] M.J. Lochhead, K.L. Bray, Phys. Rev. B 52 (1995) 15763.

[4] K. Gatterer, G. Pucker, H.P. Fritzer, Phys. Chem. Glasses 38 (1997) 293.

[5] J. de Bonfils, G. Panczer, D. de Ligny, S. Peuget, B. Champagnon, J. Nucl. Mater. 362 (2007) 480.

[6] F. Thevenet, G. Panczer, P. Jollivet, B. Champagnon, J. Non-Cryst. Solids 351 (2005) 673.
[7] N. Ollier, G. Concas, G. Panczer, B. Champagnon, T. Charpentier, J. Non-Cryst. Solids 328 (2003) 207.

[8] N. Ollier, G. Panczer, B. Champagnon, G. Boulon, P. Jollivet, J. Lumin. 94-95 (2001) 197.

[9] S.-G. Lee, K.Y. Lee, S.Y. Cho, Y.Y. Yoon, Y. Kim, Geosci. J. 10 (2006) 103.

[10] S. Chaussedent, V. Teboul, A. Monteil, Curr. Opin. Solid State Mater. Sci. 7 (2003) 111.

[11] S.-D. Mo, W.Y. Ching, Phys. Rev. B 57 (1998) 1521915227.

[12] X. Zhao, D. Vanderbilt, Phys. Rev. B 65 (2002) 075105.

[13] S.H. Wemple, Phys. Rev. B 7 (1973) 4007.

[14] S. Sen, Z. Xu, J.F. Stebbins, J. Non-Cryst. Solids 226 (1998) 29.

[15] J.M. Delaye, D. Ghaleb, Phys. Rev. B 61 (2000) 14481.

[16] T.F. Soules, J. Non-Cryst. Solids 49 (1982) 29.

[17] J.M. Delaye, L. Cormier, D. Ghaleb, G. Calas, J. Non-Cryst. Solids 293-295 (2001) 290.

[18] C. Brecher, L.A. Riseberg, J. Non-Cryst. Solids 40 (1980) 469.

[19] C.B. Layne, W.H. Lowdermilk, M.J. Weber, Phys. Rev. B 16 (1977) 10.

[20] G. Cormier, J.A. Capobianco, C.A. Morrison, A. Monteil, Phys. Rev. B 48 (1993) 16290.

[21] A.N. Cormack, J. Du, J. Non-Cryst. Solids 293-295 (2001) 283.

[22] M. Nogami, T. Nagakura, T. Hayakawa, J. Lumin. 86 (2000) 117.

[23] F. Rocca, M. Ferrari, A. Kuzmin, N. Daldosso, C. Duverger, F. Monti, J. Non-Cryst. Solids 293-295 (2001) 112.

[24] S. Sen, J. Non-Cryst. Solids 261 (2000) 226. 